\title{
The use of an endotracheal tube for cannulation of left superior vena cava via coronary sinus for repair of a sinus venosus atrial septal defect
}

\author{
ANDREW M HARRIS, SAID SHAWKAT, JOHN S BAILEY \\ From the Sub-Regional Cardiothoracic Unit, Department of Surgery, Groby Road Hospital, Leicester
}

SUMMARY A reinforced cuffed endotracheal tube was used to drain blood from a left superior vena cava via the coronary sinus during patch repair of a sinus venosus defect in a 65 year old patient. This approach produced good drainage and a bloodless operative field.

It is estimated that a left superior vena cava is present in approximately $0.3 \%$ of the general population $^{12}$ and in $4 \%$ of patients with heart disease. $^{3-6}$ Commonly it drains into the coronary sinus. If adequate cardiopulmonary bypass is to be established for intra-atrial procedures, such as closure of atrial septal defects, the left sided superior vena cava must be drained adequately. A cardiotomy suction cannula may be used to control the left superior vena caval flow through the coronary sinus. ${ }^{7}$ Alternatively, the left superior vena cava can be cannulated directly. ${ }^{8}$ The use of the cuffed, reinforced endotracheal tube (Mallinckrodt) not only removes more blood from the operative field than use of a cardiotomy suction cannula but also is easier and less time consuming than direct cannulation and snaring of the persistent left superior vena cava.

\section{Case report}

A 65 year old man first presented with atrial fibrillation, heart failure, and clinical signs of an atrial septal defect, which was confirmed by catheter studies. He refused operation because his symptoms improved on medical treatment. Ten years later he again presented with increasing dyspnoea; on this occasion he consented to operation. Cardiac catheter studies again confirmed an atrial septal defect and 3.6:1 left to right shunt, pulmonary hypertension, a left sided superior vena cava draining to the coronary sinus, and an absent innominate vein.

Surgical repair was performed through a median

Requests for reprints to Mr John S Bailey, FRCS, Department of Cardiothoracic Surgery, Groby Road Hospital, Groby Road, Leicester LE3 9QE. sternotomy. As expected, there was no innominate vein. A large left superior vena cava and small right superior vena cava drained with both the superior and inferior pulmonary veins into a sinus venosus abnormality which communicated with the left atrium in a conventional way through a defect high in the atrial septum. Cardiopulmonary bypass was established from snared cannulas in the right superior and inferior vena cava to the aortic root. The patient was cooled to $28^{\circ} \mathrm{C}$, the aorta was cross clamped, and cardioplegia was used. A right atriotomy was made and the atrial septal defect and large coronary sinus were noted. A size 6 reinforced cuffed endotracheal tube (Mallinckrodt) was then inserted via the coronary sinus into the left superior vena cava and connected to the venous drainage pipes. We controlled blood leakage around the tube and sustained good drainage by intermittently adjusting the volume of the endotracheal tube cuff. We did not need to use snugging of the left superior vena cava or pump suckers to maintain a dry and clear operative field. Throughout the procedure venous drainage from the left superior vena cava was adequate with a small adjustment of the cuff. The cannula was removed from the coronary sinus before atriotomy repair. Cardioversion with a DC shock was used to convert ventricular fibrillation to nodal rhythm as the patient came off bypass. He required pacing for about 24 hours; after this the preoperative rhythm of atrial fibrillation resumed.

\section{Discussion}

Surgical repair of an atrial septal defect in adults and in patients over 60 years of age has been reported before. ${ }^{9-11}$ As an isolated anomaly a left sided 
superior vena cava that drains into the coronary sinus is of no significance. However, assessment of anomalous venous drainage, such as a left superior vena cava, either preoperatively by conventional radiology, catheter studies, and echocardiography, or at operation is essential when operative repair of congenital anomalies of the heart is being undertaken. We found that cannulation of the left superior vena cava via the coronary sinus with a cuffed endotracheal tube produced adequate bypass simply and quickly and a clear field of vision. This improved the technical ease with which the atrial septal defect was closed with a patch.

\section{References}

1 Cha EM, Khoury GH. Persistent left superior vena cava. Radiologic and clinical significance. Radiology 1972;103:375-81.

2 Abrams HD, ed. Abrams angiography: vascular and interventional radiology. 3rd ed. Boston: Little, Brown, 1983:936.

3 Winter FS. Persistent left superior vena cava. Survey of the world literature and report of thirty additional cases. Angiology 1954;5:90-132.
4 Campbell M, Deuchar DC. The left-sided superior vena cava. Br Heart J 1954;16:423-39.

5 Gensini GG, Caldina P, Casaccio F, Blount SG. Persistent left superior vena cava. Am $J$ Cardiol 1959;4:677-85.

6 Fraser RS, Dvorkin J, Rossoll R, Eidem R. Left superior vena cava. A review of associated congenital heart lesions, catheterisation data and roentgenographic findings. Am J Med 1961;31:711-6.

7 Lenox C, Zuberbuhler JR, Park SC, et al. Absent right superior vena cava with persistent left superior vena cava: implications and management. Am J Cardiol 1980;45:117-22.

8 Pugliese P, Murzi B, Aliboni M, Eufrate S. Absent right superior vena cava and persistent left superior vena cava. Clinical and surgical considerations. Cardiovasc Surg 1984;25:134-7.

9 Hanlon CR, Barner HB, Willman VL, Mudd JG, Kaiser GC. Atrial septal defect: results of repair in adults. Arch Surg 1969;99:275-80.

10 Gault JH, Morrow AG, Gay WA Jr, Moss J Jr. Atrial septal defect in patients over the age of forty years. Clinical and haemodynamic studies and the effects of operation. Circulation 1968;37:261-72.

11 Yalav E, Brown AH, Braimbridge MV. Surgery for atrial septal defect in patients over 60 years of age. Report of surgical correction in 12 patients. $J$ Thorac Cardiovasc Surg 1971;62:788-92. 